\title{
Correction to: Evaluation of iron and manganese removal effectiveness by treatment plant modules based on water pollution index; a comprehensive approach
}

\author{
Nima Kalvani ${ }^{1}$ - Alireza Mesdaghinia ${ }^{1,2} \cdot$ Kamyar Yaghmaeian $^{1,3} \cdot$ Samaneh Abolli $^{1,4} \cdot$ Sommayeh Saadi $^{1}$. \\ Mahmood Alimohammadi $^{1,2,5}$ (D) Abdollah Rashidi Mehrabadi ${ }^{6}$
}

Published online: 15 July 2021

(C) Springer Nature Switzerland AG 2021

Correction to: J Environ Health Sci Engineer. https://doi.org/10.1007/s40201-021-00665-2

The order of arthor(s) was incorrect in the original article. The original article has been corrected.

Publisher's note Springer Nature remains neutral with regard to jurisdictional claims in published maps and institutional affiliations.

The online version of the original article can be found at https://doi.org/ 10.1007/s40201-021-00665-2

Mahmood Alimohammadi

m_alimohammadi@tums.ac.ir

$\triangle$ Abdollah Rashidi Mehrabadi a_rashidi@sbu.ac.ir

1 Department of Environmental Health Engineering, School of Public Health, Tehran University of Medical Sciences, Tehran, Iran

2 Center for Water Quality Research (CWQR), Institute for Environmental Research (IER), Tehran University of Medical Sciences, Tehran, Iran
3 Centre for Solid Waste Management (CSWM), Institute for Environmental Research (IER), Tehran University of Medical Sciences, Tehran, Iran

4 Health Center of Garmsar, Semnan University of Medical Sciences, Semnan, Iran

5 Health Equity Research Center (HERC) Tehran University of Medical Sciences, Tehran, Iran

6 Civil, Water and Environmental Engineering Faculty, Shahid Beheshti University A.C., Tehran 19839-69411, Iran 